DOI 10.15593/2224-9354/2017.2.9

УДК 316.344 .4

К.А. Антипьев, Е.А. Лазукова, Г.В. Разинский

\title{
МУНИЦИПАЛЬНАЯ ВЛАСТЬ И МЕСТНЫЕ СООБЩЕСТВА: ОСОБЕННОСТИ ВЗАИМОДЕЙСТВИЙ (К ПОСТАНОВКЕ ИЗ ПРОБЛЕМЫ СОЦИОЛОГИЧЕСКОГО ИССЛЕДОВАНИЯ)
}

\begin{abstract}
Местные сообщества представляют собой один из видов социальной организации жителей, складывающейся на определенной локальной территории. При этом в социологической науке не существует единой точки зрения на рассмотрение местного сообщества. Не существует даже единого определения данных общностей и их специфических характеристик. В статье выделяются исследовательские подходы к местным сообществам. Авторы статьи акцентируют внимание на том, что местные сообщества следует рассматривать в контексте их взаимодействия с муниципальной властью. В идеальной модели муниципальная власть является выразителем интересов местного сообщества, но в реальности мы видим и конфликтные отношения, и отношения недоверия этих субъектов. Поэтому авторы придерживаются идеи, что муниципальную власть и местные сообщества не следует рассматривать в разных плоскостях. Эффективность муниципальной власти во многом зависит от поддержки местных сообществ, которые могут не только одобрять действия местных властей, но и участвовать в выработке и реализации решений. К сожалению, активность местных сообществ можно охарактеризовать как низкую. Да и сама местная власть не всегда готова мириться со вниманием местных сообществ в отношении своей деятельности. Это связано с тем, что интересы местных сообществ и властных структур могут расходиться. Выявление проблем взаимодействия муниципальной власти и местных сообществ необходимо для гармонизации их отношений, повышения уровня взаимного доверия. Наиболее значимо это в городских сообществах, где интересы являются более разнообразными и противоречивыми.

Ключевые слова: местное сообщество, муниципальная власть, социальные взаимодействия, муниципальные образования, муниципальные служащие, социальная активность, гражданское общество.
\end{abstract}

Актуальность исследования взаимоотношений муниципальной власти и местных сообществ обусловлена, прежде всего, отсутствием системного представления в фундаментальной социологической науке взаимоотношений между местным сообществом и муниципальными структурами управления. Современное управление требует отказа от принципов директивности и подразумевает переход $к$ самоуправлению, базирующемуся на взаимодействии институтов гражданского общества и структур государственной (муниципальной) власти. Подобные устойчивые интеракции становятся основой социаль-

(С Антипьев К.А., Лазукова Е.А., Разинский Г.В., 2017

Антипьев Константин Анатольевич - канд. социол. наук, доцент кафедры социологии и политологии ФГБОУ ВО «Пермский национальный исследовательский политехнический университет», e-mail: konstant77@mail.ru.

Лазукова Евгения Андреевна - канд. социол. наук, доцент кафедры социологии и политологии ФГБОУ ВО «Пермский национальный исследовательский политехнический университет», e-mail: e.las@mail.ru.

Разинский Геннадий Вениаминович - старший научный сотрудник, заведующий лабораторией социологии ФГБОУ ВО «Пермский национальный исследовательский политехнический университет», e-mail: benyoma@mail.ru. 
ных отношений. Конфликтный характер таких отношений, необходимость их регулирования порождают потребность в исследовании взаимоотношений органов муниципального управления и местных сообществ, что выявляет практическую значимость данного исследования. Конфликты на локальном уровне могут перерастать свою территориальность, заставляя обращать на них внимание региональной и федеральной власти [1, с. 40]. Актуальность исследования взаимодействий обусловлена также необходимостью определения эффективности работы муниципальных служащих путем выявления обратной связи со стороны населения, муниципального управления и местных сообществ, что выявляет практическую значимость данного исследования.

В условиях кризиса, падения уровня жизни населения потребность во взаимодействии общества и власти еще более актуализируется, так как отношения между ними приобретают более обостренный характер, обнажаются социальные противоречия, которые сглаживались в относительно благоприятные годы. Понимание взаимных ожиданий власти и местных сообществ позволит не только прогнозировать определенные формы активности и выявлять очаги возможных конфликтов, а также их потенциальных носителей, но и разработать концепцию социальной политики, ориентированной на стимулирование процессов активизации структур гражданского общества в регионе, обновление институтов муниципальной власти и совершенствование их кадрового потенциала. Повседневная жизнь людей так или иначе связана с поддержкой, разрешениями, консультациями, которые дает муниципальная власть [2, с. 28].

В научной социологической литературе рассматривается преимущественно отношение местных жителей к муниципальной власти, удовлетворенность решения местных проблем. Изучаются либо интеграция в местные сообщества иммигрантов, либо теоретические аспекты проблематики местных сообществ. Существует и крайняя точка зрения, что местных сообществ в России нет, а можно говорить лишь о населении локальных территорий. Исходя из этого, с одной стороны, практически остаются не изученными внутренняя структура, социальные установки и поведение, потребности групп горожан, входящих в то или иное сообщество, механизмы их функционирования. С другой стороны, остается малоизученным муниципальное чиновничество как социальная страта городского социума со своими характерологическими, социокультурными особенностями, ценностями, потребностями. В результате - взаимодействия местной власти и местных сообществ, их точки соприкосновения, противоречия взаимодействий этих субъектов исследованы и представлены в отечественной социологии слабо. Вне внимания исследователей остаются факторы, препятствующие такому взаимодействию, как и те, которые такое взаимодействие стимулируют. И самое главное - обследуемые группы не анализируются в их системном единстве и противоречии. 
Можно выделить следующие исследовательские подходы:

а) к изучению местных сообществ в России: местное сообщество как социальная система (В.Н. Иванов, В.И. Патрушев, Л.П. Морозова); как локальное объединение жителей (Е. Варшавер, С. Моргунов); как основа гражданского общества на местном уровне (Т.И. Макогон, Р.В. Петухов, М.И. Юркина);

б) к изучению муниципальных служащих: последние обычно рассматриваются как часть бюрократических структур управления наряду с государственными служащими (работы К. Кавелина, Б. Чичерина, А. Градовского, В.Е. Гимпельсона, Е.В. Охотского, А.В. Оболонского, В.С. Магуна и др.).

К ключевым темам, близким к рассматриваемой, можно отнести следующие:

- практики взаимодействия с представителями властных структур, в том числе изменение их «забюрократизированности» (И.В. Мерсиянова, Н.М. Великая, В.Е. Гимпельсон, Н.М. Плискевич);

- активность населения как упреждение коррупции во властных структурах (Ю.А. Нисневич, А.В. Тихомиров, В.Л. Римский);

- принуждение представителей местного сообщества к исполнению закона (Э.Л. Панеях, Е.С. Алексеенкова, М.В. Рац);

- ассоциации, возникающие у населения при упоминании представителей структур управления (М.К. Горшков, Д.В. Поликанов);

- достоинства и недостатки работы на муниципальной службе, ее престижность (М.К. Горшков, Н.Г. Чевтаева, В.Ф. Анурин);

- удовлетворенность местного сообщества муниципальным управлением (К.В. Харченко, Л.А. Бершадская);

- общественная активность местного сообщества (Т.Е. Ворожейкина, Л.Д. Гудков, Д.А. Волков);

- формирование властными структурами имиджа и репутации территорий Российской Федерации (И.С. Важенина, С.Г. Важенин).

Вместе с тем, несмотря на обилие публикаций, существует дефицит исследований, системно описывающих и объясняющих взаимоотношения между органами муниципального управления и местными сообществами. До измерения особенностей их взаимодействий большинство исследователей не доходит.

В российских реалиях основным актором местного самоуправления принято считать муниципальные управленческие структуры. Конечно, в концепции вертикального построения власти, выстроенной иерархическим образом. Хотя, исходя из Конституции РФ, Европейской хартии местного самоуправления, местное самоуправление осуществляется «снизу», от населения. Линейно-иерархическое построение власти имеет один весьма существенный изъян: оно исключает участие различных групп местного населения в управлении в целом и в учете их интересов и потребностей в частности, так как отсутствует канал, обеспечивающий коммуникацию управленцев и управ- 
ляемых. Власть лишь условно указывает, что действует во имя интересов местных сообществ, но возрастание активности этих сообществ власть тяготит.

На самом деле основным субъектом местного самоуправления должно быть местное сообщество, так как именно оно в идеале должно определять развитие местного самоуправления, контролировать деятельность муниципальной власти [3, с. 16]. Существует мнение, что активизация местных сообществ должна идти параллельно с реформированием системы местного самоуправления [4, с. 44].

Выделяют пять основных признаков местного сообщества: население (как общность людей), место (территория), социальные связи и взаимодействия, общие интересы, чувство сообщества (социально-психологическая идентификация в сообществе). В силу этого дается ряд определений местных сообществ:

- местное сообщество - общность людей, объединенных местом проживания, социальной инфраструктурой, общими интересами, ценностями, традициями, обычаями;

- местное сообщество - сообщество людей, проживающих на определенной территории и объединенных общими интересами в решении вопросов жизнедеятельности посредством использования и развития местных материальных и социальных ресурсов на принципах самоуправления;

- местные сообщества - объединения людей на основе общности интересов и образа жизни.

В социологической литературе предпринимаются попытки для типологизации местных сообществ [5, с. 49-55]. Местное сообщество может быть относительно небольшим, или на одной территории может быть несколько местных сообществ (крупный город). Иногда исследователи указывают, что местное сообщество складывается из соседских сообществ [6, с. 26]. Чем больше размер населенного пункта, тем сложнее социальная структура проживающего в нем населения, тем более размытыми становятся границы сообщества и слабее соседские связи, выше атомизация не только жителей друг от друга, но и жителей и власти. Аналогичным образом дело обстоит и с муниципальной властью: она все больше дистанцируется от населения, может возникать взаимное недоверие.

Между членами местного сообщества всегда должны существовать отношения взаимодействия по различным вопросам социальной жизни, начиная от простых интеракций соседского характера и заканчивая активным участием в управлении территорией. Социальные связи и взаимодействия внутри местного сообщества могут устанавливаться по различным поводам, не обязательно затрагивающим групповые нужды или нужды сообщества. Разветвленность, разнообразие, воспроизводство и устойчивость социальных связей и взаимодействий в свою очередь укрепляют местное сообщество как социальную общность.

В условиях крупного города можно выделить местное сообщество как все население города, а также сообщества внутри его, воспроизводящие тер- 
риториальное деление города. Так, жители отдаленных от центра города районов, имеют более устойчивую идентификацию с жителями этого района и его территорией, чем жители центральных районов города. Следует учитывать и мигрантов, и транзитное население, которое лишь временно привязано к локальной территории и местному сообществу [7, с. 41].

Сложность взаимодействия местных сообществ и местных структур управления обусловлена целым рядом обстоятельств как связанных со спецификой поселения, в котором существует сильная социокультурная дифференциация от групп с развитой структурой потребностей и интересов до тех из них, которые ограничены решением сиюминутных, первичных нужд, так и с различной степенью осознания себя как части того или иного сообщества. Вследствие этого контрагенту - управленческим структурам - сложно выделить в конгломерате потенциально существующих сообществ те из них, которые могут стать реальным спарринг-партнером в решении существующих задач того или иного муниципалитета. Впрочем муниципальные структуры управления и сами не слишком склонны к каким-либо активным контактам с «курируемым» ими населением, предпочитая объектный тип управления, лишь вербально обозначаемый ими как местное самоуправление. Можно согласиться с А.М. Киселевой, что исторически в России «развитие горизонтальных неполитических социальных связей, образующихся автономными ассоциациями граждан, всегда наталкивалось на противодействие государства» $[8$, с. 67]. Логично отмечается, что как на местное сообщество, так и на местное самоуправление до сих пор оказывает влияние советская политическая традиция, которая состоит в сохранении управленческого менталитета старого образца [9, с. 159]. С другой стороны, доминирование объектного подхода в управлении подпитывается самими жителями, которые, формально принадлежа к тому или иному местному сообществу, не стремятся к реально инициативным действиям, ожидая от властей решения своих проблем. В этом проявляется действие одного из основных препятствий для налаживания сотрудничества управляющих и управляемых - доминирования в обществе патерналистских настроений, имеющих социоисторические корни и приобретших характер синдрома, пронизывающего всю ткань социальных отношений, в том числе и реально, и потенциально существующие сообщества и муниципальные управленческие структуры [10, с. 82-84; 11, с. 540; 12, с. 62-64].

Таким образом, основной научной проблемой, решаемой в ходе реализации исследования, посвященного взаимоотношениям муниципий и местных сообществ, является существование сложного комплекса противоречий, сужающих поле возможного взаимодействия основных контрагентов отношений в обследуемой поселенческой общности - местного населения, входящего в тот или иной тип местного сообщества, и муниципальных структур управления, а также поиск путей их преодоления или, по крайней мере, смягчения. 
Ведущими проблемами отношений, порождающих напряженность во взаимодействии этих двух субъектов, являются, во-первых, отсутствие взаимного доверия, отсутствие баланса интересов, отсутствие реальных диалоговых форм, во-вторых, противоречие между требованиями, предъявляемыми к сотрудникам органов муниципального управления как к представителям данных учреждений, и требованиями к ним со стороны местного сообщества и, в-третьих, напряженность в отношениях внутри каждого из субъектов. Также исследователи указывают и на низкое качество муниципального управления и непрофессионализм кадров [13, с. 106].

Исходя из сформулированной проблемы, требующей преодоления противоречия между населением города, представленным конгломератом различных сообществ и муниципальными структурами управления, конкретной задачей, направленной на его преодоление, является всестороннее изучение отношений в обследуемом социуме в контексте социальных реалий данного типа поселений.

Это предопределило параметры объекта, предмета и цели исследования, а также постановку операциональных задач, обеспечивающих решение общей конкретной задачи проекта.

Объект исследования - местные сообщества в лице представителей групп городского населения и муниципальные структуры управления в лице муниципальных служащих различного статуса.

Предмет исследования - характер взаимоотношений местных сообществ и органов муниципального управления.

Цель исследования - определить особенности взаимоотношений органов местного самоуправления и местных сообществ, изучить их формы и содержание.

В соответствии с выделенной целью реализуются следующие операционные задачи:

- определить иерархию и функциональность выявленных местных сообществ;

- обозначить и описать их структуру и характеристики;

- выявить целевые группы специалистов местного самоуправления;

- выявить роль и значение социогенетических факторов в отношениях местного сообщества и муниципальной власти, в частности, влияние на эти отношения и на каждый обследуемый субъект патерналистского синдрома;

- выявить степень участия местных сообществ в решении местных проблем как автономно, так и совместно с властью;

- выделить и проанализировать оценки, а также установки специалистов органов муниципальной власти в отношении местных сообществ и способах взаимодействия с ними;

- определить степень взаимного недоверия местных сообществ и муниципальной власти;

- выявить основные противоречия, препятствующие пониманию и конструктивным взаимодействиям местных сообществ и муниципальной власти; 
- определить перспективы повышения взаимного доверия и точки возможных взаимодействий местных сообществ и муниципальной власти;

- обозначить направления взаимодействий местных сообществ и муниципальной власти.

Все это необходимо учитывать при определении содержательных аспектов исследования, что предполагает изучение следующих социальных параметров, характеризующих обе обследуемые группы, жителей города, представляющих местные сообщества и городское чиновничество, презентированное муниципальными служащими. Местные сообщества и муниципальные структуры представляют две ипостаси одной более широкой общности - городского социума. И те и другие (власти и сообщества) едины и противоречивы в структуре городского социума, и поэтому задача исследователя состоит в выявлении точек контакта и дисконтакта, т.е. в выяснении того, что их объединяет и что приводит к противоречиям, а в крайних случаях к конфронтации. Очевидным является факт, что оценка государственными и муниципальными служащими своей деятельности имеет существенные отличия от оценки их деятельности местными сообществами [14, с. 83].

Для реализации цели и задач настоящего исследования предполагается использование следующих методов сбора и анализа социальной и социологической информации:

1) анализ данных официальной статистики, показывающей структуру местных сообществ;

2) анализ данных структуры, качественного и количественного состава органов местного самоуправления;

3) разработка на основании теоретической концепции (программы) двух специализированных социологических инструментариев (анкет): одного для изучения мнения жителей города как потенциальных участников местных сообществ, другого - для опроса представителей муниципальной власти;

4) построение квотной модели выборочной совокупности, отражающей структуру местных сообществ и структуру сотрудников органов муниципальной власти;

5) проведение социологического опроса на основании разработанной выборки (примерный объект выборки: 500 единиц наблюдения - респонденты, представляющие основные группы населения Перми, входящие в то или иное местное сообщество, и 300 единиц наблюдения - специалисты муниципальных структур управления);

6) систематизация, обработка и анализ полученных данных в соответствии с целями и задачами исследовательского проекта, а также и с учетом результатов агломерирования массива опрошенных жителей города в зависимости от их принадлежности к тому или иному сообществу;

7) применение дополнительных методик (фокус-групп, контрольных интервью). 
Информация будет сниматься по двум аналогичным инструментариям, обеспечивающим сопоставимость полученных данных и сравнимость их базовых характеристик:

- личностные характеристики (пол, возраст, образование, семейное положение, профессия, должность, жилищные условия, материальный статус);

- принадлежность к тому или иному сообществу (кем себя ощущают: жителем города, района, микрорайона, дома, в котором живут; работником предприятия, членом коллектива, в котором работают; членом семьи (мужем, женой, отцом, сыном); членом политического и конфессионального сообщества); иерархия ролей;

- социально-стратификационная идентификация и самоидентификация, подверженность патерналистскому синдрому (социальное происхождение, условия воспитания, место в стратификационной пирамиде, отношение к рынку и поведение в нем, отношение к социальному расслоению, оценка роли государства, потребность в социальной поддержке);

- пространственная идентификация и самоидентификация (отношение к городу, оценка города, ориентация на миграцию);

- участие в управлении и самоуправлении горожан в рамках того или иного местного сообщества (факт участия/неучастия в нем, мотивы; готовность/неготовность участвовать, мотивы) и муниципальных служащих вне рамок своей профессиональной деятельности;

- оценка сторонами (представителями местных сообществ и муниципальными служащими) своих контактов друг с другом: цель контактов, их частота, к кому обращались, какое отношение, удовлетворенность работой управленческих структур и отношением со стороны персонала, поведением посетителей в муниципальных учреждениях управления;

- возможность сотрудничества и взаимодействия представителей местных сообществ с муниципальными структурами (цели, содержание, мотивы возможности/невозможности сотрудничества, ожидаемая и реальная результативность);

- оценка сторонами собственной социальной активности и активности своих визави;

- факторы, стимулирующие/препятствующие активизации взаимоотношений муниципальных властей и структур местных сообществ;

- оценка обеими сторонами личностных, социокультурных, социальнопсихологических, профессиональных качеств представителей своих групп и другой стороны;

- выявление иерархии местных сообществ по степени самоидентификации с ними, проведение сравнительного анализа ориентированности их на взаимодействие/противостояние с муниципальными служащими; 
- оценка сторонами взаимодействия остроты основных городских проблем;

- оценка муниципальными служащими отношений в органах муниципальной власти возможностей социального продвижения и профессионального роста, общей удовлетворенности своим положением и статусом.

Проведение исследования позволит обеспечить возможные пути сотрудничества институциональных и гражданских структур местного управления:

1) выявить противоречия во взаимодействии местного сообщества и органов муниципальной власти;

2) выделить уровень имеющихся социальных взаимодействий;

3) выявить особенности взаимного восприятия местных сообществ и органов местного самоуправления;

4) описать иерархию, структуры и функциональность выявленных местных сообществ;

5) определить проблемные зоны функционирования местных сообществ, с одной стороны, и структур муниципального управления (включая их персонал) - с другой;

6) выявить наиболее значимые факторы, влияющие на взаимоотношения муниципальных структур управления и местного сообщества;

7) определить пути, а также возможности снижения влияния патерналистского синдрома на городской социум в целом и на местные сообщества и муниципальные структуры в частности;

8) определить конструктивные перспективные способы взаимодействий рассматриваемых субъектов с учетом их интересов;

9) разработать на этой основе концепцию региональной социальной политики, ориентированной на развитие местного самоуправления на принципах гражданского общества.

Результаты исследования, обоснованные выводы можно использовать при составлении программы социально-экономического развития края; для стимулирования вовлечения граждан в решение местных проблем; в целях повышения управляемости местных сообществ через учет их интересов.

Гражданское общество во многом и складывается из местных сообществ, осознающих, что решение многих проблем зависит от них самих. Осознание этого приводит к необходимости либо давления на муниципальную власть, либо вступления с ней в диалог. Развитые местные сообщества способны удовлетворять свои ведущие нужды через взаимодействие с муниципальной властью.

Статья подготовлена в рамках исследовательского проекта № 17-13-59001, финансируемого Российским гуманитарным научным фондом. 


\section{Список литературы}

1. Антипьев К.А. Конфликтное взаимодействие местного сообщества и муниципальной власти // Научные ведомости Белгородского государственного университета. Философия, социология, право. - 2014. - Т. 29, № 16. - С. 39-44.

2. Шпак Л.Л., Токмашева Ю.В. Мобилизационно-управленческий механизм взаимодействия муниципальной власти с местными сообществами // Вестник Томского государственного университета. - 2015. - № 399. - С. 28-33.

3. Пылин В.В. Местные сообщества как основа гражданского общества / С.-Петерб. ин-т внешнеэкон. связей, экономики и права. - СПб., 2001. - 234 с.

4. Садыков А.Р. Коммуникативный дискурс в системе «муниципальная власть - местное сообщество» // Человеческий капитал. - 2015. - № 6. - С. 42-45.

5. Макогон Т.И. Типология местных сообществ // Вестник Томского государственного университета. - 2013. - № 366. - С. 49-55.

6. Кокарев И. Соседские сообщества: путь к будущему России. - М.: Прометей, 2001. - 140 с.

7. Бурмистров А.С. Местное сообщество как субъект самоуправления // Известия высших учебных заведений. Правоведение. - 2000. - № 5. - С. 36-42.

8. Киселева А.М. Местное сообщество как основа формирования гражданского общества в России // Вестник Омского университета. Экономика. 2007. - № 1. - С. 64-68.

9. Афонин М.В. Местное самоуправление и городское сообщество // Вестник Ярославского государственного университета. Гуманитарные науки. 2012. - № 3. - С. 158-162.

10. Разинский Г.В. Патернализм: структурные характеристики // Современное общество: вопросы теории, методологии, методы социальных исследований: материалы XI Всерос. науч. конф., посвящ. 90-летию со дня рождения проф. 3.И. Файнбурга. - Пермь: Изд-во Перм. нац. исслед. политехн. унта, 2012. - С. 82-85.

11. Разинский Г.В. Патернализм как синдром [Электронный ресурс] // Социология в системе научного управления: материалы IV Bсерос. социол. конгр. / Ин-т социологии РАН; Ин-т социально-полит. исслед. РАН; Рос. гос. социальный ун-т. - М., 2012. - С. 539-540.

12. Разинский Г.В. Молодежь: устойчивость патерналистского синдрома и перспективы его преодоления // Вестник Пермского национального исследовательского политехнического университета. Социально-экономические науки. - 2014. - № 4. - С. 60-65.

13. Байков Н.М., Невеличко Л.Г. Особенности функционирования местных сообществ городских и сельских поселений в социологическом измерении // Власть и управление на Востоке России. - 2011. - № 3. - С. 106-113. 
14. Лазукова Е.А. Оценка государственной службы чиновниками и населением // Вестник Пермского национального исследовательского политехнического университета. Социально-экономические науки. - 2014. - № 1. - С. 77-84.

\section{References}

1. Antip'ev K.A. Konfliktnoe vzaimodeistvie mestnogo soobshchestva i munitsipal'noi vlasti [Conflict interaction between the local community and municipal authorities]. Nauchnye vedomosti Belgorodskogo gosudarstvennogo universiteta. Filosofiia, sotsiologiia, pravo, 2014, no. 16, vol. 29, pp. 39-44.

2. Shpak L.L, Tokmasheva Iu.V. Mobilizatsionno-upravlencheskii mekhanizm vzaimodeistviia munitsipal'noi vlasti s mestnymi soobshchestvami [Mobilization and management interaction mechanism between municipal authorities and local communities]. Vestnik Tomskogo gosudarstvennogo universiteta, 2015, no. 399, pp. 28-33.

3. Pylin V.V. Mestnye soobshchestva kak osnova grazhdanskogo obshchestva [Local communities as the basis of civil society]. Saint-Petersburg, S.-Peterb. in-t vneshneekon. sviazei, ekonomiki i prava, 2001, 234 p.

4. Sadykov A.R. Kommunikativnyi diskurs v sisteme: "munitsipal'naia vlast'mestnoe soobshchestvo [Communicative discourse in the system: municipal authority - local community]. Chelovecheskii capital, 2015, no. 6, pp. 42-45.

5. Makogon T.I. Tipologiia mestnykh soobshchestv [Typology of local communities]. Vestnik Tomskogo gosudarstvennogo universiteta, 2013, no. 366, pp. 49-55.

6. Kokarev I. Sosedskie soobshchestva: put' k budushchemu Rossii [Neighboring communities: the path to the future of Russia]. Moscow, Prometei Publ., 2001, 140 p.

7. Burmistrov A.S. Mestnoe soobshchestvo kak sub"ekt samoupravleniia [Local community as a subject of self-administration]. Izvestiia vysshikh uchebnykh zavedenii. Pravovedenie, 2000, no. 5, pp. 36-42.

8. Kiseleva A.M. Mestnoe soobshchestvo kak osnova formirovaniia grazhdanskogo obshchestva $\mathrm{v}$ Rossii [Local community as a basis for Russian civil society formation]. Vestnik Omskogo universiteta. Ekonomika, 2007, no. 1, pp. 64-68.

9. Afonin M.V. Mestnoe samoupravlenie i gorodskoe soobshchestvo [Local government and urban community]. Vestnik Iaroslavskogo gosudarstvennogo universiteta. Gumanitarnye nauki, 2012, no. 3, pp. 158-162.

10. Razinskii G.V. Paternalizm: strukturnye kharakteristiki [Structural characteristics of paternalism]. Sovremennoe obshchestvo: voprosy teorii, metodologii, metody sotsial'nykh issledovanii: materialy KhI Vseros. nauch. konf., posviashch. 90-letiiu so dnia rozhdeniia prof. Z.I. Fainburga [Proc. All-Russ. Conf. "Modern society: theoretical questions, methodologies, social research methods"]. Perm, PNRPU, 2012, pp. 82-85.

11. Razinskii G.V. Paternalizm kak sindrom [Paternalism as a syndrome]. Sotsiologiia $v$ sisteme nauchnogo upravleniia: materialy IV Vseros. sotsiol. kongressa [Proc. All-Russ. Congress "Sociology in the system of scientific man- 
agement"]. Moscow, In-t sotsiologii RAN; In-t sotsial'no-polit. issled. RAN; Ros. gos. sotsial'nyi un-t. Publ., 2012, pp. 539-540.

12. Razinskii G.V. Molodezh': ustoichivost' paternalistskogo sindroma i perspektivy ego preodoleniia [Youth: the sustainability prospects for overcoming the paternalistic syndrome]. PNRPU Sociology and Economics Bulletin, 2014, no. 4, pp. 60-65.

13. Baikov N.M., Nevelichko L.G. Osobennosti funktsionirovaniia mestnykh soobshchestv gorodskikh i sel'skikh poselenii v sotsiologicheskom izmerenii [Features of local urban and rural communities functioning in the sociological dimension]. Vlast' i upravlenie na Vostoke Rossii, 2011, no. 3, pp. 106-113.

14. Lazukova E.A. Otsenka gosudarstvennoi sluzhby chinovnikami i naseleniem [Assessment of civil service by the officials and the population]. PNRPU Sociology and Economics Bulletin, 2014, no. 1, pp. 77-84.

Оригинальность статьи - $86 \%$

Получено 31.01.2017

K.A. Antipyev, E.A. Lazukova, G.V. Razinsky

\title{
MUNICIPAL AUTHORITIES AND LOCAL COMMUNITIES: SPECIAL FEATURES OF THEIR RELATIONS (SETTING THE PROBLEM OF SOCIOLOGICAL RESEARCH)
}

\begin{abstract}
Local communities represent a social organization type of people, which develops itself within a certain locality. Sociology has no common viewpoint on local communities, as well as no single definition of such communities and their specific features. The article highlights certain scientific approaches to studying local communities and emphasizes the need to consider them in the context of their correlation with municipal authorities. The ideal model of municipal authority appears a representation of interests in a local community. However, the reality demonstrates conflicting relations and the incredulity of the two parties. Thus, the authors suggest considering municipal authorities and local communities within a single socio-cultural environment. The authors claim that the efficiency of municipal authorities largely depends on the approval and disapproval expressed by local communities. They can also participate in the development and implementation of certain decisions. However, local communities' level of commitment appears relatively low, while the authorities are not always ready to accept interference with their activities. This demonstrates the divergence of the interests in these two groups, which requires defining the problems in their collaboration in order to harmonize the relations and to promote mutual trust. The authors state the importance of building these relations in urban communities that appear to be more diverse and controversial.

Keywords: local community, municipal authorities, social interactions, municipalities, municipal officials, social activity, civil society.

Konstantin A. Antipyev - Candidate of Sociological Sciences, Associate Professor, Dept. of Sociology and Political Science, Perm National Research Polytechnic University, e-mail: konstant77@mail.ru.

Evgeniya A. Lazukova - Candidate of Sociological Sciences, Associate Professor, Dept. of Sociology and Political Science, Perm National Research Polytechnic University, e-mail: e.las@mail.ru.

Gennady V. Razinsky - Senior Researcher, Head of the Laboratory of Sociology, Perm National Research Polytechnic University, e-mail: benyoma@mail.ru.
\end{abstract}

